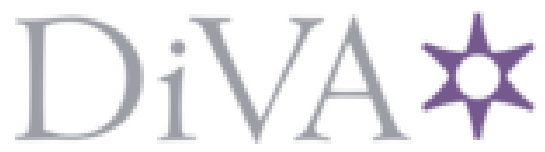

http://www.diva-portal.org

This is the published version of a paper presented at Proceedings of ASME Turbo Expo 2020: Turbomachinery Technical Conference and Exposition.

Citation for the original published paper:

Tian, S., Gutierrez Salas, M. (2021)

Numerical Sensitivity Study on the Design of a Transonic Aeroelastic Compressor Rig In: , GT14565 US: ASME Press

https://doi.org/10.1115/GT2020-14565

N.B. When citing this work, cite the original published paper.

Permanent link to this version:

http://urn.kb.se/resolve?urn=urn:nbn:se:kth:diva-295291 
September 21-25, 2020, Virtual, Online

GT2020-14565

\title{
NUMERICAL SENSITIVITY STUDY ON THE DESIGN OF A TRANSONIC AEROELASTIC COMPRESSOR RIG
}

\author{
Simeng Tian, Mauricio Gutierrez Salas \\ KTH, Royal Institute of Technology \\ Stockholm, Sweden
}

\begin{abstract}
In modern transonic compressors, forced response can occur at high-order modes and at high-reduced frequencies. To understand this phenomenon, a new cascade test-rig is being built to provide configurations and validations for the forced response simulations of transonic compressors. With the aid of Computation Fluid Dynamics (CFD) optimizations, the test section shape was roughly determined before. The purpose of this paper is to provide the finalization process of the cascade test-rig design including a transonic nozzle and blade tip gaps. Hence, the steady and unsteady simulations are employed based on three different geometries: test section, test rig with nozzle, and test rig with $1 \%$ tip gap. The simulation results show that the unsteadiness in the test rig is related mainly to the oscillation performance of the shock waves in the passage. The comparison in the test rig with and without tip gap confirms that tip gap can reduce the unsteady pressure. The unsteady pressure reflection due to the tailboards, especially on the bottom tailboards, indicates this problem needs to be thoroughly considered in the installation and testing.
\end{abstract}

\section{INTRODUCTION}

Forced response in modern transonic compressors, take place mainly at high-order modes at their respective high natural frequencies. However, in previous rigs, the test blade oscillating frequencies were much lower, which means that there is a lack of experimental validation for the forced response research in transonic compressors at high vibrational frequencies[1,2]. Standard configurations are in need to assess the accuracy of these methods by the comparison between experiments and numerical simulations [3]. This has been the reason for building a new aeroelastic cascade wind tunnel. It will investigate the unsteady transonic flow while the compressor blade vibrating frequency is up to $2000 \mathrm{~Hz}$ (reduced frequency $\omega^{*}>2$ ). The measured aerodynamic damping of the new cascade test rig will provide a reference for the future transonic compressor forced response research. The cascade is being built at KTH to investigate the aeroelastic performance of the transonic compressor at high-reduced frequencies. The CFD-aided design gives a near periodic flow as indicated in the previous analyses [4].

The cascade wind tunnel experiments are one of the most dominant methods to investigate the aeroelastic phenomena in compressors, and very used to validate the aeroelastic simulations. As an aeroelastic tool, the most important requirement for the cascade wind tunnel is its accuracy. However, the flow in a wind tunnel cannot be as ideal as in near-flight conditions. In most cases, it is a trade-off between the size of the models and in the accurate representation of the steady and unsteady uniformities [5]. Usually, there are some geometric factors, such as, tip gaps, tailboards, sidewalls, which might affect the performance. Designers can use optimization techniques to increase periodicity with the change of these factors in the steady simulations [4]. On the other hand, there also exist different methods to correct the performance of the test object in the wind tunnel [6-8]. However, there is no clear picture of how these factors influence the aeroelastic performance of the cascade wind tunnel. Besides, the unsteadiness of the transonic cascade flow is highly sensitive to the change in geometry. Therefore, the study of these factors might also point out an aspect of why some existing test rigs lack accuracy in the experiments, where the understanding of these factors will introduce improvements to these rigs. Due to the inherent sensitivity of transonic flows, the inlet boundary layer and the tip leakage flow will lead to variations of the unsteady pressure, which will lead to a change in the flow periodicity and the unsteady aeroelastic performance.

The limiting space of the tunnel will cause many differences, such as the boundary layer. For example, experiments in a 14inch United Aircraft Corporation transonic wind tunnel showed that the boundary layer took around $1 / 4$ of the flow area [5]. The effect becomes much more important since the cascade wind tunnel needs to keep the periodicity on the middle blades. Tip gap is another significant factor in the compressor design [9]. The tip leakage flow has a significant influence on the steady and aeroelastic behaviors in compressor [10-12]. Tip gap will inevitably cause the redistribution of the wall pressure on the blades. 
This paper provides the final cascade test-rig design with a transonic nozzle and a corresponding tip gap. The steady and unsteady flow results have been studied when the blade oscillates at a high-order mode. The results from the simulations will serve as the baseline for the future parametric study on the unsteady performance of the new test rig.

In the first part, a transonic nozzle is designed and attached to the test section, providing the design of the entire test rig. Unlike the typical aeroelastic research in turbomachinery, the periodicity of the cascade flow needs to be analyzed and assessed. Therefore, in the second part, a steady flow analysis has been performed to validate the cascade flow simulation concerning a typical compressor flow simulation under the operating conditions. Due to the sensitivity of the transonic flow, the tip leakage flow is investigated to understand their behavior on the periodicity of the cascade flow, which will then lead to variations in the unsteady pressure. Finally, the cascade unsteady flow has been analyzed when the blade oscillates at a high-order mode.

\section{KTH TRANSONIC AEROELASTIC TEST RIG}

\section{Blade profile}

The blade profile is based on the first rotor of the VINK-6 compressor, designed and optimized by Lejon [13]. Due to the diffusion of the shroud, the pitch to chord ratio varies from 0.7179 at the leading edge to 0.7259 at the trailing edge. For the test profile, the value of 0.7224 at the mid-chord has been taken into consideration. The inlet total pressure and temperature are modified based on the working conditions of the already existing scroll compressor at $\mathrm{KTH}$ in order to provide the required transonic flow.

Table. 1 Comparison of VINK- 6 and the test profile

\begin{tabular}{c|c|c}
\hline Parameters & VINK6 & Test profile \\
\hline Chord length $(\mathrm{c} / \mathrm{mm})$ & \multicolumn{2}{|c}{104.6} \\
\hline Maximum thickness $(\mathrm{t} / \mathrm{mm})$ & \multicolumn{2}{|c}{2.03} \\
\hline Stagger angle $(\mathrm{deg})$ & \multicolumn{2}{|c}{64.78} \\
\hline Pitch chord ratio & $0.7179-$ & 0.7224 \\
& 0.7259 & \\
\hline Inlet Mach number & \multicolumn{2}{|c}{1.2} \\
\hline Inlet static pressure $\left(\mathrm{p}_{\mathrm{in}} / \mathrm{kPa}\right)$ & 39.8 & 74.94 \\
\hline Inlet temperature $\left(\mathrm{T}_{\mathrm{in}} / \mathrm{K}\right)$ & 267.8 & 238.3 \\
\hline
\end{tabular}

\section{Test section design}

The aeroelastic testing to measure the aerodynamic damping can be divided in three methods: free flutter, travelling wave mode controlled flutter, and influence coefficient controlled flutter. Free flutter is normally used as a validation testing method in a typical design or a real turbomachinery. In travelling wave mode, the blades are subjected to a controlled vibration at a certain interblade phase angle. The aerodynamic work can be obtained during the measurement. The influence coefficient method was invented in 1955 [14], firstly as an aeroelastic tool for discrete lift surface calculations in early aerodynamic strip theories. Previous studies show that the coupling effect due to the blade vibration, not only affects the moving blade, but also the neighbouring blades. Moreover, the unsteady pressure at the adjacent blades have a dominant role, and then it decays significantly on the other neighbouring blades. Thus, the unsteady pressure effects will be wellpredicted only by the middle three blades (blade +1 , blade 0 and blade-1) theoretically, shown in Figure 1. Five blades are used in the test section.

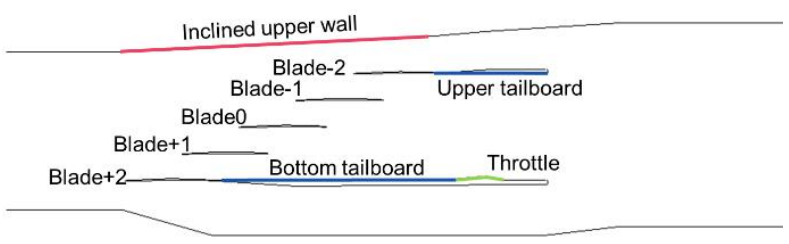

Figure 1. Schematic view of the test rig

With CFD optimization, the two-dimensional test section geometry has been previously determined. A one-outlet shape was used to provide a simple design with near periodic flow with the $5 \%$ blade loading difference. Response surface methods were used to achieve an optimal geometry [15]. According to the previous study, the steady solution shows that the inclined upper wall, tailboards and the throttle are used to increase the periodicity. For example, the upper wall, which is normally slotted or perforated in the transonic wind tunnel, is used to eliminate the shockwave reflections and to avoid choking. For the current design, it has been considered solid but inclined to avoid choking and to aid the simulations. If the unsteady reflection on this wall interacts with complex shockwave structures, the experimental accuracy should be carefully corrected. Tailboards are essential components and proved to be important in the aeroelastic research [16]. The throttle is used to generate a non-uniform back pressure to adjust the periodicity. However, it might also causes unsteadiness during the blade oscillation. The unsteady impact from these components are noticed in the numerical analyses, and might be reflected as system errors in the experimental research.

\section{Transonic nozzle design}

The transonic nozzle is divided into three sections. The first is an already existing contraction in the KTH lab, shown in Figure 2. The second contraction part is designed with a five order polynomial method in the contraction design. Five order contraction section design method is confirmed to be the most efficient and accurate solution by Bell [17] in 1988. The third part is designed with the Foelsch method [18]. The strength of the Foelsch method is to provide an analytical solution for the divergent curvature. In overall, the nozzle flow area from inlet to outlet is transformed from $250 \mathrm{~mm} \times 250 \mathrm{~mm}$ to $180 \mathrm{~mm} \times 70 \mathrm{~mm}$. 


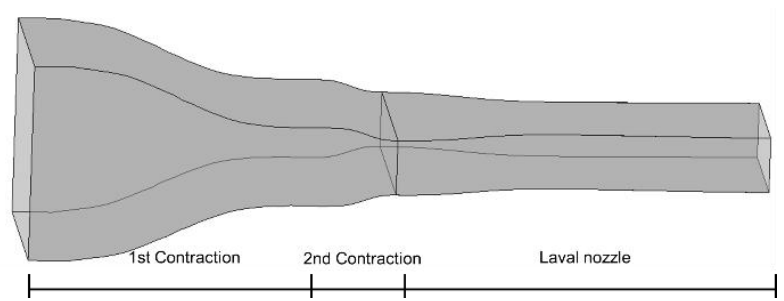

Figure 2. The transonic nozzle sections

\section{METHODOLOGY}

\section{Grid description}

The whole test rig and grids are shown in Figure 3. Double O blocks mesh surrounding the blade were applied to provide a smooth transition on the size of the grids. The first layer thickness is of $0.002 \mathrm{~mm}$, with a maximum $\mathrm{y}+$ of 2.5 . The number of elements for the different domains, test section, test rig with nozzle, and test rig with $1 \%$ tip gap, is of approximately $3.5 \mathrm{M}, 4 \mathrm{M}$, and $4.5 \mathrm{M}$ respectively.

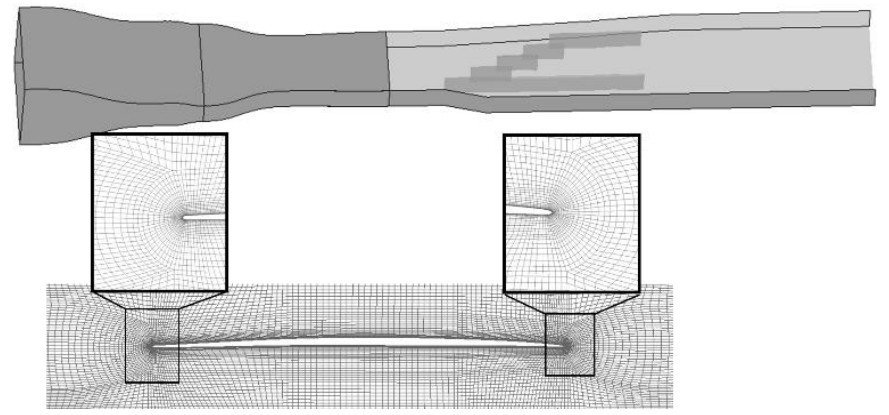

(a) Flow domain

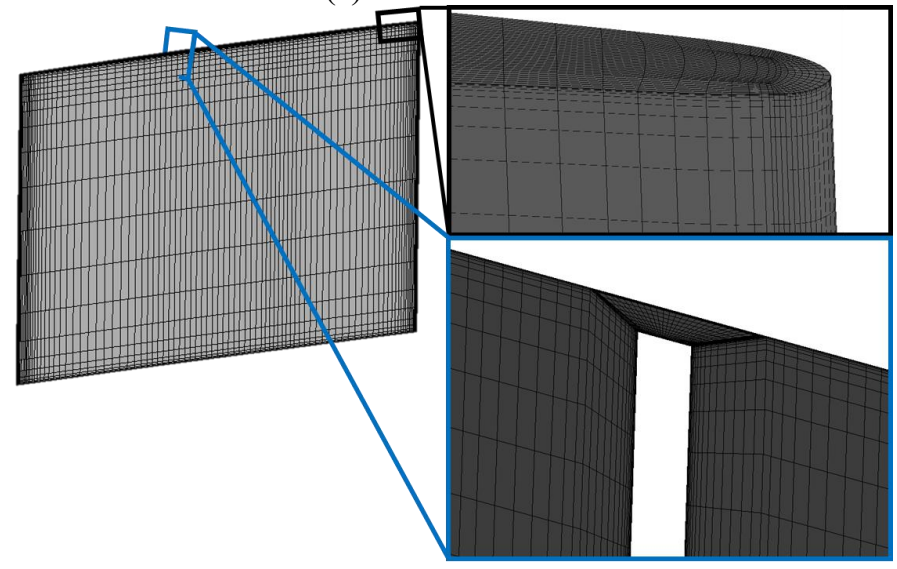

(b) Grids on the blade

Figure 3. Flow domain and the mesh around the blade

\section{Mode shape}

The modal analysis was conducted with ANSYS APDL. The blade's fifth mode shape is shown in Figure 4.

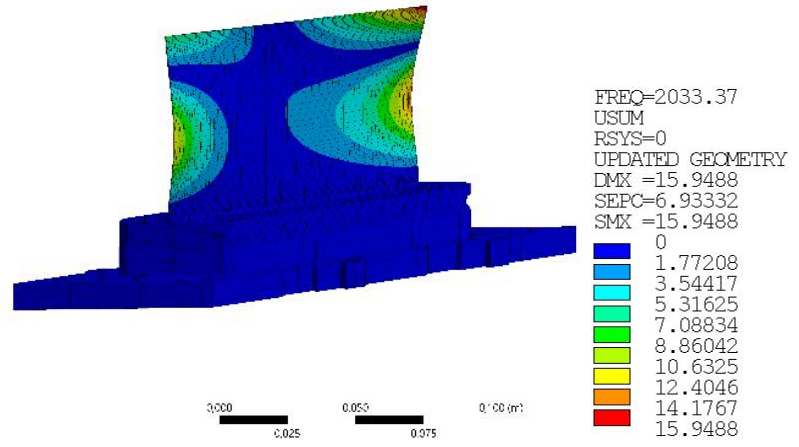

Figure 4. Blade displacement of the fifth mode shape

The mode's frequency is $2033.4 \mathrm{~Hz}$ and the reduced frequency is 3.44 , which was calculated with Equation 1.

$$
k=\frac{2 \pi f c}{V_{r e f}}
$$

Where, $f$ means the blade vibration frequency, $c$ is the chord length. $V_{\text {ref }}$ represents a reference velocity, the inlet velocity has been used for the test rig. The oscillation amplitude is set as $0.5 \mathrm{~mm}$, which represents approximately $0.5 \%$ of the chord length.

\section{Numerical setup}

The ANSYS CFX software was employed in this numerical study. SST k- $\omega$ turbulence model was used in the steady and unsteady Reynolds averaged Naiver-Stokes (RANS) simulations. The advection and turbulence terms were resolved with a high-resolution scheme and the transient behaviours were predicted with the second order backward Euler scheme. Inlet turbulence level was set to $1 \%$ based on the wind tunnel air supply [19]. The unsteady performance was carried out with 40 time steps per period.

\section{Numerical validation}

A repeated blade passage mesh assembly is generally used when the cascade wind tunnel has several blades and perfect periodicity is required. However, the employment of this mesh assembly may cause inaccuracies due to interpolation errors at every interface. For instance, one attempt is to use the conventional line-matched multi-block mesh [20]. Another attempt is presented in this paper, where the effect of the interfaces are studied. Figure 5 provides a scaling view of the interface between two blade passages at the top endwall. The case in Figure 5(a) uses the repeated blade passage mesh and it enforces exactly the same mesh for all the blade passages, but it comes with a disadvantage that the interface is not one to one anymore and instead an interpolation takes place.

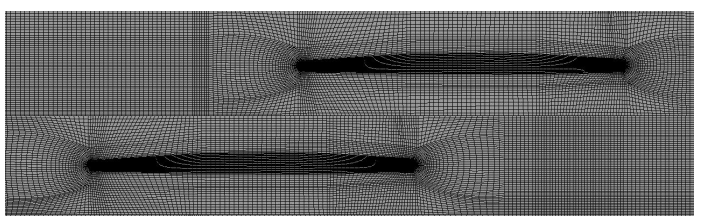


(a) Mesh with interface

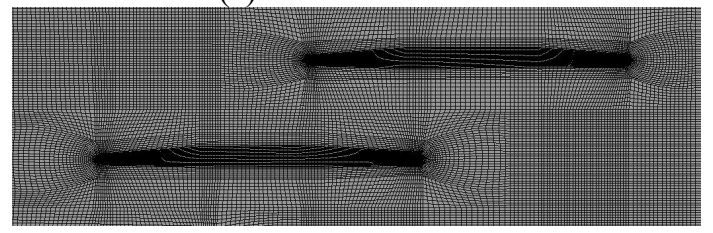

(b) Mesh without interface

Figure 5. Scaling view on the mesh

Figure 6 shows the comparison on the insentropic Mach number with and without interface at $50 \%$ and $90 \%$ span.
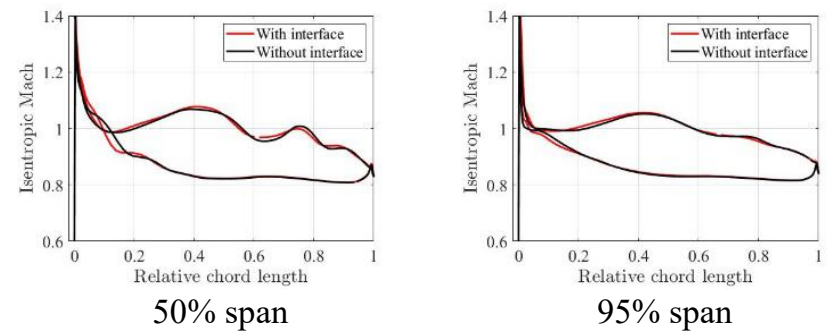

Figure 6 . Blade loading of blade 0

The blade loading near the leading edge is consequently affected by the interface, which indicates the shockwave prediction is different with and without interface. This impact is reduced at $90 \%$ span, which could be due to the weak inlet shockwave. The overall difference in the steady aerodynamic force for these two cases is $1.29 \%$. It proves that the interface of the mesh does have an impact on the performance, but not as much as other factors, such as using different turbulence models. At the end, the mesh without the interface was the one used in all the simulations.

The mesh sensitivity on element number was conducted for validation, as shown in Figure 7 . The test rig with $1 \%$ tip gap (about $4.5 \mathrm{M}$ elements) was selected as the reference. To eliminate the effect from $\mathrm{y}^{+}$, the mesh number increases mainly in pitchwise direction, while the first layer thickness on the blades and sidewalls are kept the same with a distance of $0.002 \mathrm{~mm}$. The steady aerodynamic force was obtained to quantify the difference in blade loadings.

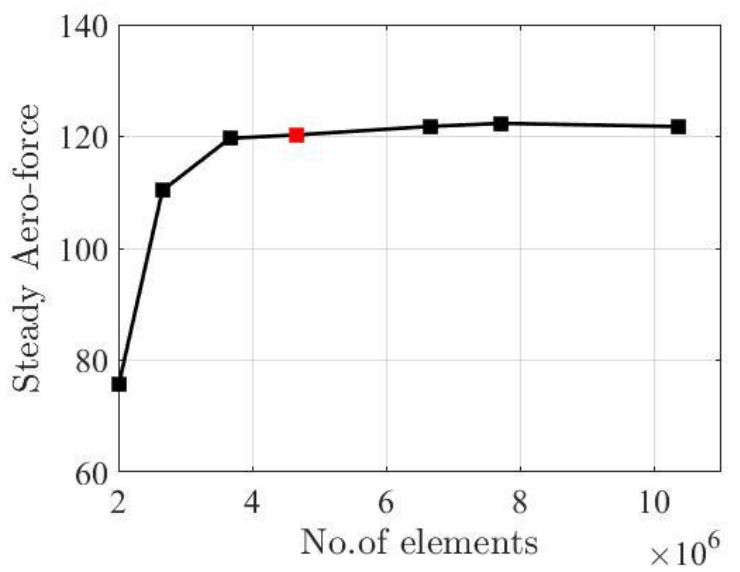

\section{Figure 7. Mesh sensitivity analysis}

While the steady aerodynamic force was obtained to evaluate the steady result with the increase of the element number, it had already converged at $3.5 \mathrm{M}$. The difference between the $4.5 \mathrm{M}$ case and the $10 \mathrm{M}$ case is of only $1.22 \%$.

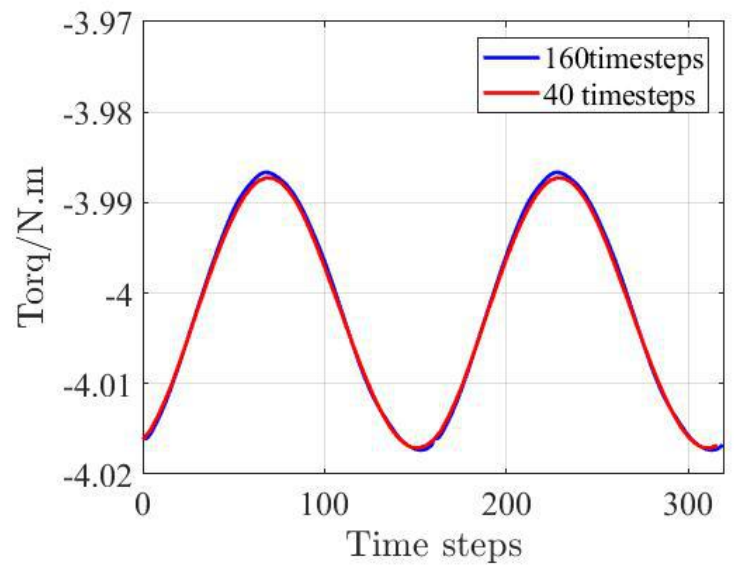

Figure 8. Comparison of the unsteadiness between 40 time steps and 160 time steps

Figure 8 shows the variant torque on blade 0 with two oscillating cycles. Since the vibration of blade0 causes unsteadiness in the pressure, the variation of its torque becomes one of the criteria to quantify the overall performance of the unsteadiness. Relative to the amplitude of the torque variation, the peak-to-peak difference between the case with 160 time steps and 40 time steps is of $2.6 \%$. This is acceptable considering the accuracy of the prediction of the unsteadiness, which includes the tip flow and the boundary layer. If the blade vibrates at $2033.37 \mathrm{~Hz}$, the time step is $12.29 \mu$ s when using 40 time steps and $3.07 \mu$ s for 160 time steps. Since the reference of the reaction time of fluids is normally several microseconds, 40 steps do not compromise the accuracy on the unsteady performance prediction for this case.

\section{RESULTS}

\section{Steady results}

The steady results of the test section, test rig with nozzle and the test rig with 1\% tip gap are compared in Figure 9. The test section shape without nozzle is not totally the same with the one with nozzle because the boundary layer effect on the bypass passages is considered. Mach Number

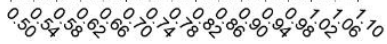

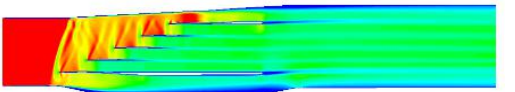

(a) Test section without nozzle 


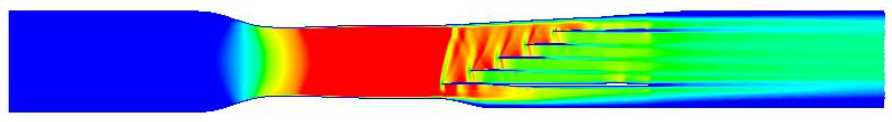

(b) Test rig without tip gap

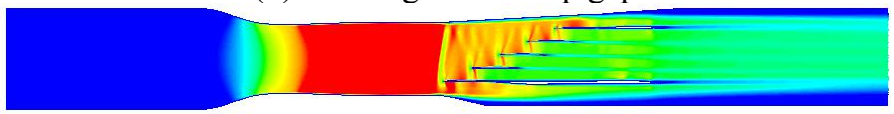

(c) Test rig with $1 \%$ tip gap

Figure 9. Mach number distribution in the mid span

Although the optimal geometry was obtained in the twodimensional simulations, the geometry needed slight changes on the bypass passages to maintain the periodicity. It should be noticed that the geometry of the test section with and without nozzle are not the same. The downstream part of the test section bottom wall has been modified, which makes the downstream flow passage narrower in the test section than in the test rig with nozzle, shown in Figure 10.a and 10.b. This layout is used to control the shock wave near the blade +2 (Figure 1). However, because of the boundary layer on the sidewalls when including the nozzle, the bottom bypass passage needs more flow area. Thus, the width of the outlet had to change from $220 \mathrm{~mm}$ to $240 \mathrm{~mm}$. The outlet pressure is changed from $128.5 \mathrm{kPa}$ to $131 \mathrm{kPa}$ in accordance.

The consideration of the tip gap also caused a slight difference in the outlet pressure. The outlet pressure is changed from $131 \mathrm{kPa}$ to $131.5 \mathrm{kPa}$ to keep the periodicity. All this is due to the high sensitivity on the transonic flow. Most of the changes on the test blade will induce the change on the periodicity.
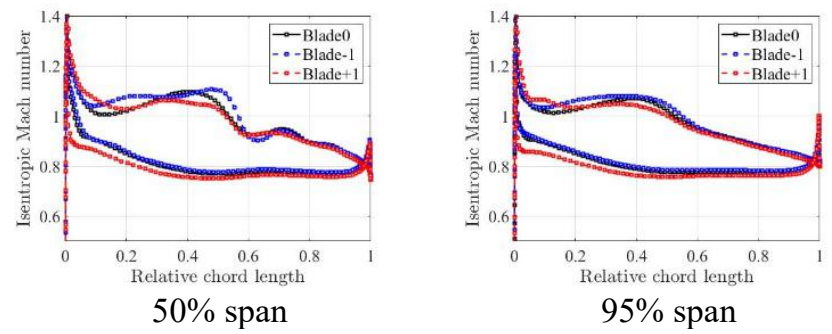

(a) Test section without nozzle
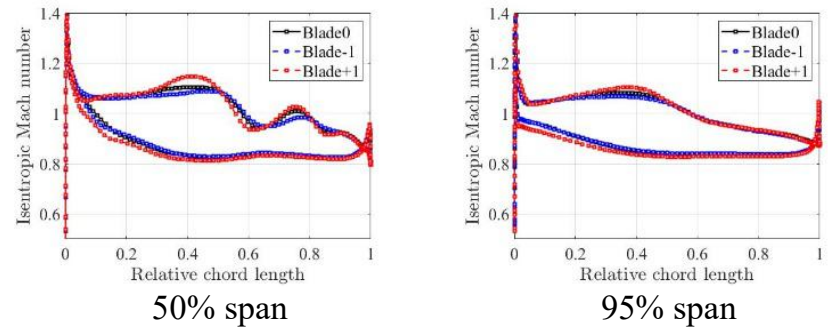

(b) Test rig without tip gap
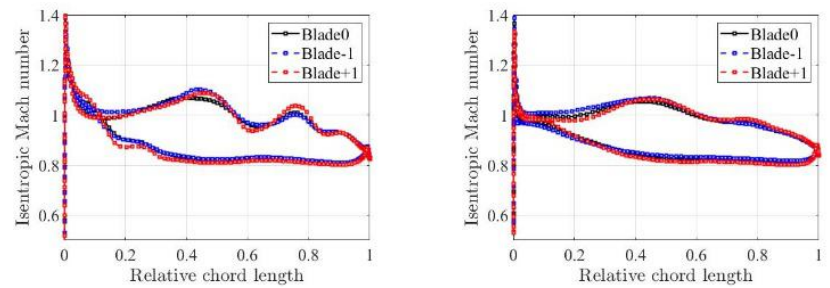

\section{$50 \%$ span}

(c) Test rig with $1 \%$ tip gap

Figure 10. Blade loading of the three middle blades

The static blade loading of the middle three blades are presented in the $50 \%$ and the $95 \%$ span to quantify the flow periodicity. Both cases, when including a nozzle and a tip gap, changed the blade loadings of these three blades. The nozzle changes the overall performance, including the leading edge and the loading while the tip gap causes considerable changes on the leading edge, but slight ones on the main part at $50 \%$ span, shown in Figure 10(b) and 10(c). It means that the leading edge part is very sensitive towards the different geometries even with $0.5 \mathrm{kPa}$ change. Generally, the blade loading at $95 \%$ span is more periodic than at mid span. As to the tip region, the tip gap cause higher differences in the $95 \%$ span compared with the mid-span. Not only the leading edge part is affected, but also the loading distribution has changed, mainly on the suction side, as presented in Figure 10(b) and 10(c).

\section{Unsteady results}

The unsteady pressure coefficient $C_{p}$ are introduced to present the unsteadiness on the blade loading. It is defined in Equation 2 , where $p$ represents the wall pressure, $A$ means the maximum amplitude of the oscillation.

$$
C_{p}=\frac{p c}{\left(p_{t, i n}-p_{s, i n}\right) A}
$$

The $C_{p}$ distribution is presented in Figure 11, where the red points represents the pressure side and the blue points show the suction side.

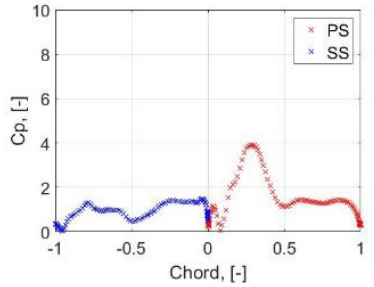

(a1) Blade-1 without tip gap

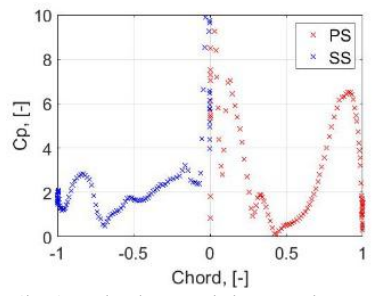

(b1) Blade0 without tip gap

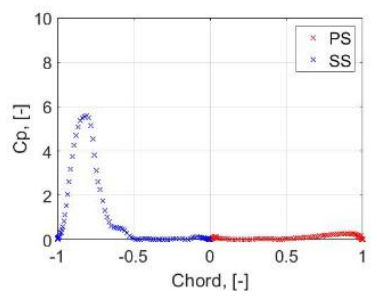

(c1) Blade+1 without tip gap

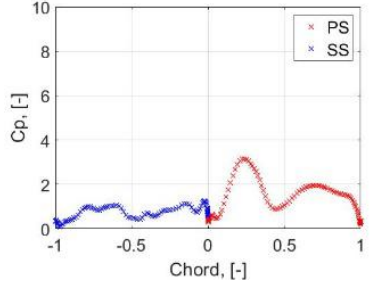

(a2) Blade-1 with $1 \%$ tip gap

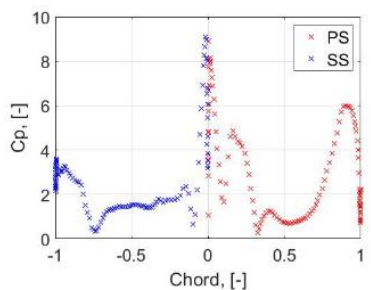

(b2) Blade0 with $1 \%$ tip gap

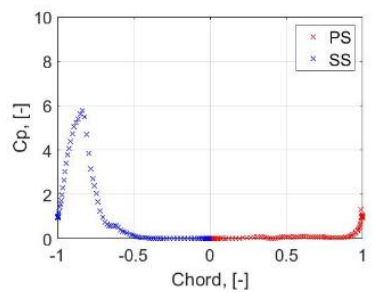

(c2) Blade+1 with $1 \%$ tip gap
Figure 11. Comparison of the unsteady pressure coefficient 
distribution between the test rig with and without tip gap at $50 \%$ span

The unsteady blade loading is higher on blade 0 , on the pressure side of the blade- 1 and on the suction side of the blade +1 . The unsteadiness on the suction side is considerable, as shown in Figure 11(a). The impact on the suction side of the blade-1 may due to the unsteady reflections on the upper wall and upper tailboard. In contrast, the effect on blade +1 and bottom tailboards seems not obvious, as shown in Figure 11(c). The pressure side of blade 0 has two parts with high unsteady blade loadings, as shown in Figure 11(b). On the suction side, the upstream part with high unsteadiness might due to the shockwave oscillations. The downstream part is because of the shockwaves inside the passage between blade-1 and blade0. On the pressure side, the upstream part has the strongest unsteadiness relevant with the flow passage between blade +1 and blade0. However, the downstream part also have high unsteadiness which seems not fitting the theory because there is no coupling effect by blade +1 due to high stagger angle.

Considering the difference in the steady state, it seems that the tip gap has no obvious effect on the unsteady blade loading at mid-span. There are still slight value changes on blade 0 and on the pressure side of blade- 1 , but this could be due to the $0.5 \mathrm{kPa}$ difference in the outlet pressure.

The unsteady blade loading at $95 \%$ span is also presented in Figure 12.

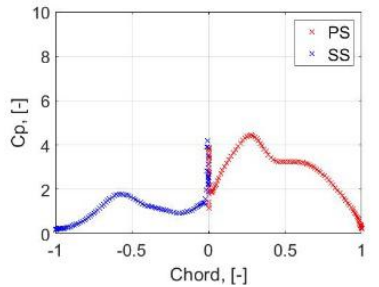

(a1) Blade-1 without tip gap

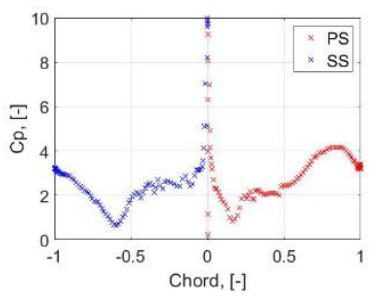

(b1) Blade0 without tip gap

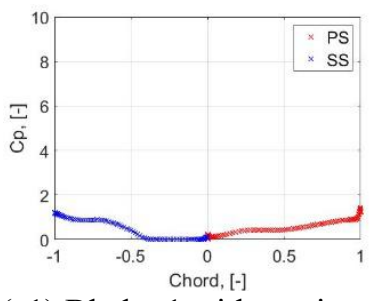

(c1) Blade+1 without tip gap

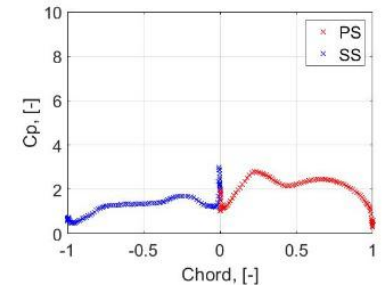

(a2) Blade-1 with 1\% tip gap

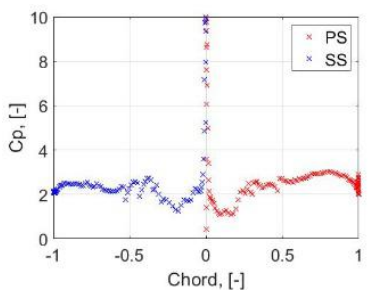

(b2) Blade0 with $1 \%$ tip gap

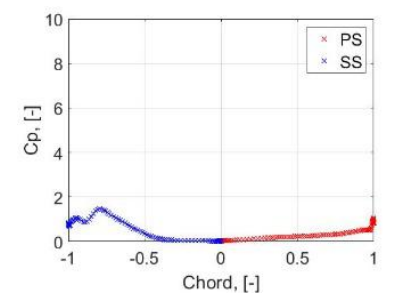

(c2) Blade+1 with 1\% tip gap
Figure 12. Comparison of the unsteady pressure coefficient distribution between the test rig with and without tip gap at $95 \%$ span

Without shockwave reflections, the unsteady blade loading decreases at $95 \%$ span when compared to mid span, especially on the suction side of the blade +1 , shown in Figure 12(c). The high unsteadiness near the leading edge is almost eliminated, compared in Figure 11(b) and Figure 12(b). However, the high unsteadiness near the trailing edge still remains. The pressure variation has been stabilized with the tip gap, where the unsteady $C_{p}$ changes from 4 to 2 generally.

In order to understand how the unsteady blade loading is generated, the unsteady pressure distribution has been analyzed during an oscillation period (T), as presented in Figure 13. The tip gap case is simultaneously compared with the one without tip.

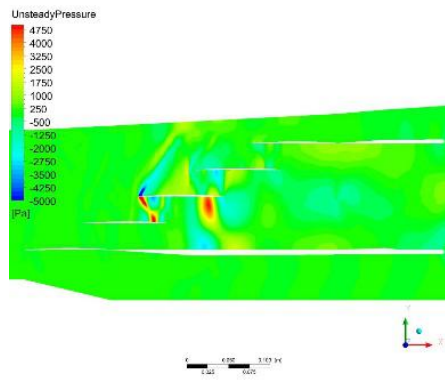

(a1) $1 / 4 \mathrm{~T}$ (without tip gap)

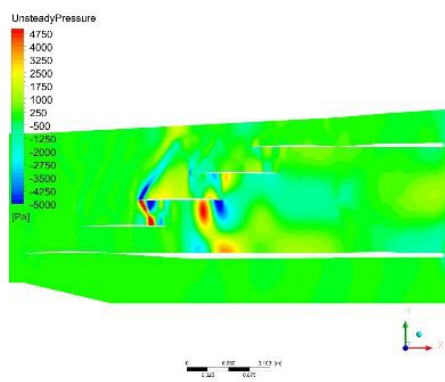

(b1) $1 / 2 \mathrm{~T}$ (without tip gap)

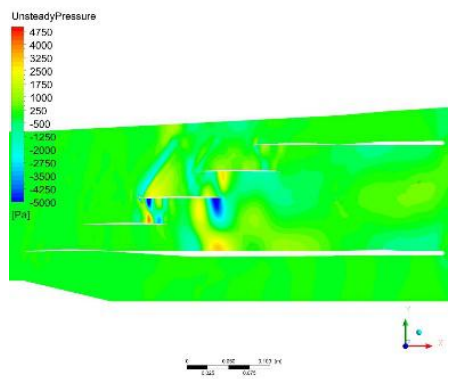

(c1) 3/4 T(without tip gap)

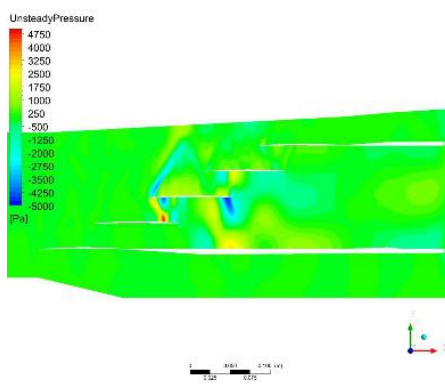

(a2) $1 / 4 \mathrm{~T}$ (with $1 \%$ tip gap)

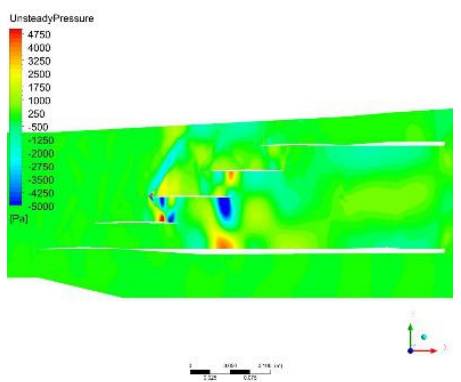

(b2) $1 / 2 \mathrm{~T}$ (with $1 \%$ tip gap)

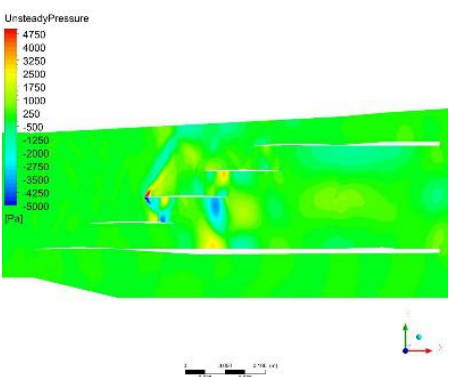

(c2) $3 / 4 \mathrm{~T}$ (with $1 \%$ tip gap)

Figure 13 . Unsteady pressure distribution at $50 \%$ span during an oscillating cycle in the test rig with and without tip gap

Most of the unsteady pressure is located near the leading edge or in the inner passage. This is due to the shock waves. It means that the shockwave oscillates within the flow passages between the middle three blades, causing high unsteady blade loadings. A noticeable phenomenon is the high unsteadiness between blade 0 and the bottom tailboard, which is obvious in Figure 13(b). It shows the pressure reflection on the tailboards, 
especially for the bottom tailboard and cannot be neglected. It proves that the unsteady pressure reflection might contribute to the high unsteadiness near the trailing edge, which is also observed in Figure 11(b). On the other side, the upper wall part with strong shockwave reflections does not show very high unsteadiness due to the blade oscillation. In overall, there is no obvious differences in the tip gap case.

Figure 14 presents the unsteady pressure distribution at 95\% span.

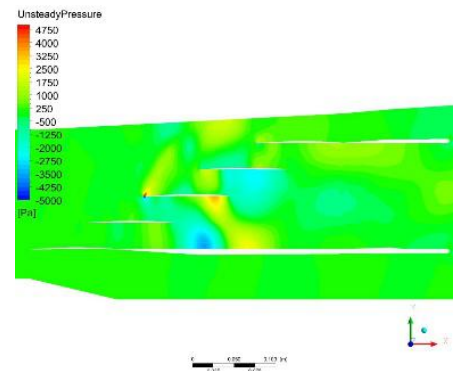

(a1) 1/4 T (without tip gap)

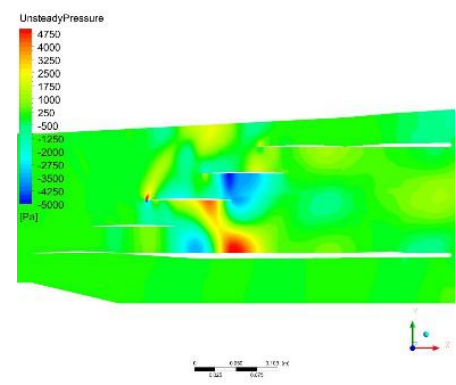

(b1) $1 / 2 T$ (without tip gap)

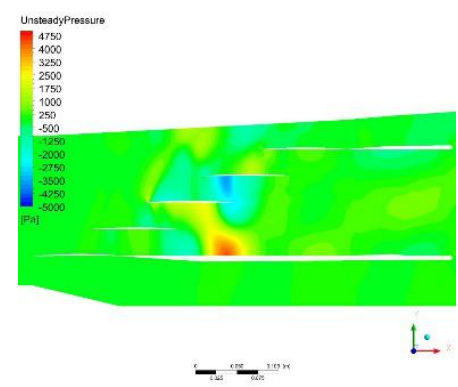

(c1) 3/4 T(without tip gap)

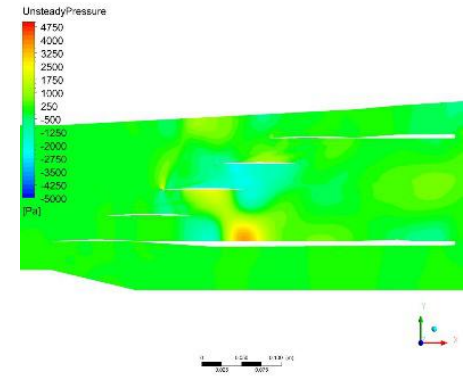

(a2) $1 / 4 \mathrm{~T}$ (with $1 \%$ tip gap)

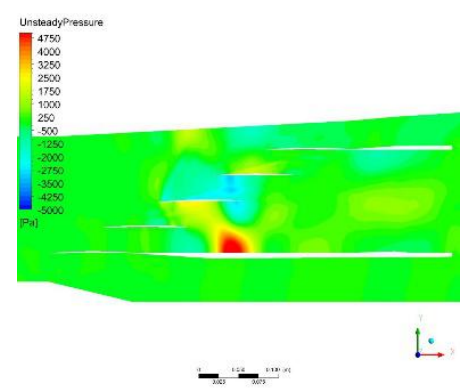

(b2) $1 / 2 \mathrm{~T}$ (with $1 \%$ tip gap)

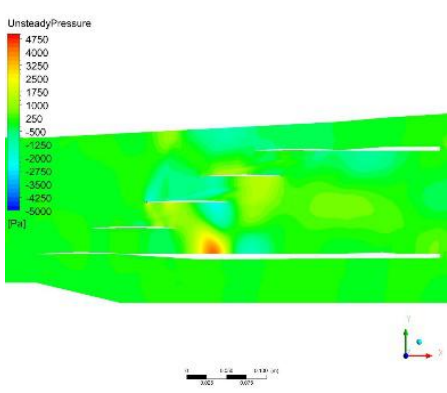

(c2) $3 / 4 \mathrm{~T}$ (with $1 \%$ tip gap)
Figure 14 . Unsteady pressure distribution at $95 \%$ span during an oscillating cycle in the test rig with and without tip gap

The implementation of the tip gap considerably changes the unsteady pressure distribution, especially in the passage between blade 0 and blade-1. The high unsteady pressure near the pressure side of blade 0 trailing edge and the pressure side of the blade- 1 seems to be reduced. At the same time, the unsteady reflections from the bottom tailboard remains with a high value.

\section{CONCLUSIONS}

In this paper, steady and unsteady simulations are applied to analyze the aeroelastic performance of a new transonic cascade wind tunnel. The conclusions can be summarized as following:

1. The periodicity and the unsteady performance is highly susceptible to transonic flows.

2. The high unsteady blade loadings are mainly caused by the shockwaves inside the passage.

3. In this case, the tip gap has a positive effect on reducing the unsteady pressure variations due to the oscillation of blade 0 .

4. The unsteady pressure reflections on the tailboards have a major impact and they need to be considered in the wind tunnel testing. The bottom tailboard causes more unsteady reflections than the upper tailboard. An absorbing material could be considered for the actual test rig.

\section{FUTURE WORK}

This research considers a preliminary unsteady analysis of the test rig. Where several problems still need to be further investigated.

1. The unsteady pressure reflections due to the upper wall or tailboards need to be well quantified. A new layout to reduce these reflections should be considered, which could be helpful for the rig design. The comparison between an infinite cascade and a real cascade wind tunnel will be performed to quantify the influence.

2. The research on geometric and unsteady parameters are very preliminary. Different tip gaps and different high-order modes are necessary in the parametric study to improve the understanding on how the different geometrical features can influence the measurement.

\section{REFERENCES}

[1] Buffum D. H, Fleeter S. S (1993). Wind Tunnel Wall Effects in a Linear Oscillating Cascade. ASME. J. Turbomach. 1993;115(1):147-156.

[2] Seeley CE, Wakelam C, Zhang X, Hofer D, Ren W (2017). Investigations of Flutter and Aerodynamic Damping of a Turbine Blade: Experimental Characterization. ASME. J. Turbomach. 2017;139(8):081011-081011-7.

[3] Fransson T.H., Verdon J.M (1993). Panel Discussion on Standard Configurations for Unsteady Flow Through Vibrating Axial-Flow Turbomachine-Cascades. Unsteady Aerodynamics, Aeroacoustics, and Aeroelasticity of Turbomachines and Propellers. Springer, New York, NY

[4] Tian, S., Petrie-Repar, P., Glodic, N., and Sun, T. (2019). CFD-Aided Design of a Transonic Aeroelastic Compressor Rig. ASME. J. Turbomach. October 2019; 141(10): 101003.

[5] Goethert, B. H. (1961). Transonic wind tunnel testing (No. AGARDOGRAPH-49). Advisory Group for Aeronautical Research and Development Paris (France).

[6] Mokry, M., Chan, Y. Y., \& Jones, D. J. (1983). Twodimensional wind tunnel wall interference (No. AGARD-AG- 
281). Advisory Group For Aerospace Research And Development Neuilly-Sur-Seine (France).

[7] Newman, P. A., \& Barnwell, R. W. (1984). Wind Tunnel Wall Interference Assessment and Correction, 1983.

[8] Malmuth, N. D., Wu, C. C., et al. (1991). Asymptotic Theory of Transonic Wind Tunnel Wall Interference. Arnold Engineering Development Center Arnold AFB TN.

[9] Day, I. J. (2016). "Stall, Surge, and 75 Years of Research." ASME. J. Turbomach. 2016; 138(1): 011001.

[10]Yang H., He L. (2004). Experimental Study on Linear Compressor Cascade with Three-Dimensional Blade Oscillation. Journal of Propulsion and Power, 2004, 20(1): 180188.

[11]Fu Z., Wang Y, Jiang X, et al. (2015). Tip Clearance Effects on Aeroelastic Stability of Axial Compressor Blades. Journal of Engineering for Gas Turbines and Power, 2015, 137(1): 012501.

[12] Besem F. M., Kielb R. E. (2016). Influence of the Tip Clearance on a Compressor Blade Aerodynamic Damping. Journal of Propulsion and Power, 2016.

[13] Lejon. M., Gronsted T., Glodic N., Petrie-Repar P.,et al (2017). Multidisciplinary Design of A Three Stage High Speed Booster. In Proceedings of ASME Turbo Expo 2017, no. GT2017-64466.
[14] Rodden, William P. (1955). An Exact Solution of the Spherical Blast Wave Problem, Phil. Mag., Vol. 46, $7^{\text {th }}$ Series, No.374, pp.317-320.

[15] Richard F. Gunst (1996) Response Surface Methodology: Process and Product Optimization Using Designed Experiments, Technometrics, 38:3, 284-28.

[16] Ott, Peter, Norryd, M., and Bölcs, A. (1998). The Influence of Tailboards on Unsteady Measurements in a Linear Cascade. In Proceedings of ASME Turbo Expo 1998, no 98-GT-572.

[17] Bell, J. H., \& Mehta, R. D. (1988). Contraction design for small low-speed wind tunnels. Report JIAA TR-84.

[18] Beckwith, I. E., \& Moore, J. A. (1955). An Accurate and Rapid Method for the Design of Supersonic Nozzles. Report NASA TN-3322.

[19] Vogt, D. M., (2005), Experimental Investigation of Three Dimensional Mechanisms in Low Pressure Turbine Flutter, Ph.D. thesis, Royal Institute of Technology, Stockholm.

[20] Tateishi A., Watanabe T., Himeno T., and Uzawa S., (2017), "Numerical method for an assessment of steady and motion-excited flow fields in a transonic cascade wind tunnel," Journal of the Global Power and Propulsion Society,1 ,pp.171183. 